\title{
Furniture aesthetics according to compatibility between Fractional geometry and golden ratio
}

\author{
Ahmed Samir kamel Ali ${ }^{1}$, Ebtesam Mohamed Khamis², Sarah Fathy Ahmed Fahmy ${ }^{3}$
}

(1) Associate professor at Interior design and furniture department -Faculty of Applied Arts - Helwan University.

(2) Associate professor at Interior design and furniture department -Faculty of Applied Arts - Helwan University.

(3)Associate professor at Interior design and furniture department -Faculty of Applied Arts -Damietta University.

\section{KEY WORDS:}

Fractional Geometry; Furniture design ; Aesthetics formation Golden ratio.

\section{ABSTRACT:}

Furniture can be considered as one of the most important elements inside the interior spaces because of its multiple features that enable it to meet the human requirements and interact with them in a convenient and comfortable manner. That beauty is achieved by integrating the dimensions of visual and sensual aspects together. To reach unique furniture units characterized by visual aesthetics and concrete functional dimensions designers must be aware of the sources of those configurations that the designer can refer to quotes, and these sources are summarized in two main directions. The first is the existence of determinants of its design and technology to organize a set of elements within the framework of a ruler of the foundations and standards, and secondly through the development of knowledge production in the modern era that results integration of science and advanced technology. Modern sciences have a special structural foundation that contribute to the construction of contemporary furniture units, especially if it is incorporated with the rules of the "Golden Ratio", that becomes an experimental entrance and a creative feature in the field of visual and applied arts.

The problem of research is the result of the proliferation of many modular furniture that lack the foundations and aesthetic standards to form the exterior, and the problem of this research is determined by how to take advantage of the characteristics of "fractal engineering" and the rules of "golden ratio" in the design of furniture units characterized by a contemporary and aesthetic dimension The research aims to harmonize fractional geometry with the golden ratio to enrich the aesthetics of furniture formation.

The research paper deals with the concept of fractal geometry, its importance and characteristics, also its relevance to nature and golden ratios and how to benefit from them in the development of innovative vocabulary for contemporary furniture units. The research concluded by conducting some design experiments on furniture units, also the most important results of the research that there is a close relationship between fractional geometry and the golden ratio, where they share several characteristics such as self-similarity, repetition, continuity and diversity of unit measurements and thus share the achievement of the aesthetics of furniture formation. 


\section{Introduction:}

Formation aesthetics directly affect the construction of the external composition of the furniture units and formulated appropriately for their function, which is positively reflected on attracting the costumer and develop aesthetic sense in order to achieve maximum sales, and build the exterior of the furniture units which depends on the ability of the designer's awareness continuous modern theories and renewable sciences that will help him in the formation of renewable designs based on scientific studies embody the main idea of design to achieve a harmonization between the aesthetic and functional values of the product also the fractional geometry as one of the modern engineering sciences that seeks to discover and interpret the complexities of cosmic as it includes many aesthetic values that contribute to the plastic construction of contemporary designs, and has become an important experimental entry and creative character in the field of visual and applied arts, through the conscious study of this science Furniture designers can create new designs with unconventional form relationships.

The research problem arose through what we suffer from the separation between the science of furniture design and science and modern trends on the academic and applied side, which resulted in the production of typical furniture that lacks many values of aesthetic formation and the problem of research lies in the following:

How to use the characteristics of "fractal geometry" and the rules of the golden ratio in the construction of aesthetic formations of contemporary furniture units?

The research aims to the compatibility between fractional geometry and the golden ratio in the creation of contemporary furniture units, the importance of the research is that it deals with the attempt to combine the science of furniture design with "fractional geometry" and the rules of the golden ratio where they were able to change the methods of design treatments for furniture units, which led to the emergence of many modern formations.

The research assumes that the fractal geometry contributes to the development of the innovative aspect of furniture designers, and the combination of fractal geometry and the golden ratio enriches the design process and contributes to the creation of modern forma- tions.

The methodology of this research follows the descriptive analytical approach to identify the most important features and characteristics of fracture geometry and golden ratio and then take advantage of those features in the design of contemporary furniture.

\section{Theoretical framework}

\section{Terms and concepts}

\subsection{Formation}

It is the thought arising from planning and organizing processes to visualize the design data visually into a three-dimensional product through the interdependence of a set of constructive relationships with each other and governed by the foundations and scientific standards and human expertise, in the light of an intellectual framework expressing its function and content.[2]

\subsection{Aesthetics}

It is an adjective on the things that give in the self-pleasure and a sense of harmony and regularity through the achievement of unity between the formal relations that we perceive with our senses, and it is one of the characteristics that characterize the structural and structural aspects, as beauty is mentioned in many Qur'anic verses - Allah says, "You have beauty when you are resting and when you are laid off". [7]

\subsection{Fractional geometry}

Irregular geometric shapes are subject to special structural systems and are concerned with the partial formations of mathematical shapes or natural elements according to a set of geometric characteristics and provide us with aesthetic formations. It can be likened to the process of breaking an object into small parts to produce irregular surfaces and shapes. Note that these parts are self-similar to each other and to the original body. A dimension concerned with the imaginary, which replaced the traditional engineering, which focused on the primary dimensions. [6] In reference to the term "Fractal" we find that it is derived from the Latin verb "Franger" which means fragmentation or breaking, and this verb was associated with the apparent properties of things, and was formulated by the mathematician "Mandelbrot" where he considered Fractal forms and Geometric formations breed and multiply digitally and are subject to mathematical laws governing the outward shape. [5] 


\section{Aesthetics of the furniture formation}

Furniture can be considered as one of the most important elements that contributes to the formation of interior spaces positively and negatively, including the aesthetic and functional values that affect the nature of those spaces and the behavior of users, the design of furniture is only a creative intellectual effort comes out in the form of aesthetic to achieve functions and requirements humanity through multiple materials and techniques. There is a close correlation between the aesthetic composition of furniture units and the desire of buying it, the exterior outline is the first aspect that attracts the user towards the acquisition or to be away from it. It also depends on a set of constructive relationships linked to each other and perceived by our senses, we can note the diversity and evolution of the exterior configurations of furniture units through successive civilizations produced furniture that distinguishes and perpetuates them through time, which was able to address the sensory and spiritual side of its users.

When it comes to our minds we shall wonder is how furniture designers can create contemporary designs characterized by renewed aesthetics of formation. In fact, research in the subject of "beauty" is not easy, it is a philosophical subject of multiple opinions and attributed to one of the three concepts associated with the provisions of the values of "beauty, truth and goodness", and the criteria of aesthetic governance are relative standards, but here we mean the foundations The standards of formation that achieve sensory satisfaction and molar in humans, which requires furniture

designers need to be aware of the sources of aesthetic formations through which they can create renewable formations through the ages, and these sources are divided into two axes as illustrated in Figure (1).

\subsection{Fixed aesthetics formation}

It means that the aesthetics of formation arise through the application of established principles and standards which act as binding laws applicable at any time and place, also includes the realization of the design foundations and relationships formed from "balance, unity, repetition, rhythm, etc", that are organized within a framework, or by quoting from our cultural heritage and incorporating it into the design of contemporary furniture directly or indirectly.

\subsection{New created aesthetics formation}

These formations originated as a result of the creation of new sciences that led to the emergence of contemporary formative trends that directly contributed to the development of the structure of the furniture units .One of the most important science trends are "fractal geometry", parametric design, morphology, and will focus in this paper on the science of "fractional engineering" for its ability to stimulate the energies of imagination and creativity for furniture designers, which is positively affects the creation of contemporary collections of furniture units with aesthetic value. Fractals carry with it a random beauty exciting senses, which makes it a new way to achieve the aesthetic dimensions.

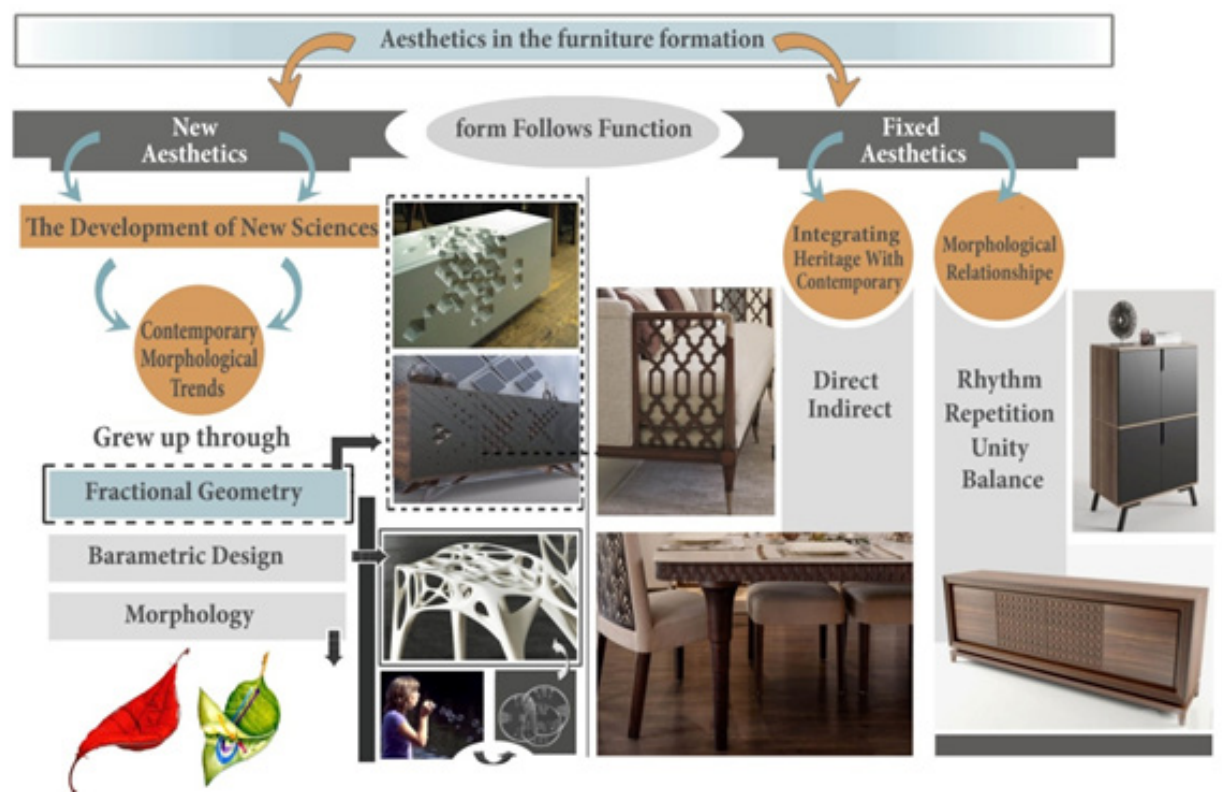

Figure 1 Sources of achieving aesthetics in the furniture formation 


\section{Fractals and nature}

Nature can be considered the main source of progress in many different fields and sciences. Thus, the vocabulary is re-arranged in contemporary design works. From this perspective, scientists have been studying and interpreting seemingly irregular phenomena, resulting in the discovery of the chaos theory. This theory, which dealt with phenomena and irregular forms in an attempt to develop scientific laws to study these systems, and this theory helped designers to discover the stimuli that contribute to obtaining sources of aesthetic renewed to reach new rules of form to free from the control of traditional formations.

It was noted that fractals, is one of the most important science on which this theory is based, were able to explain the nature of the seemingly irregular forms and the systematic description of them, and this is evident in the winding swirls of water and land and beaches ,also the nature of irregular formations in plants and animals and changed the natural phenomena that this science has been able to decipher it through the efforts of mathematicians by analyzing the structural relationships inherent in the systems and formations of nature, and this science opened horizons for designers and artists to discover new formative and structural inputs in their works of art.

We can categorize "fractures" into two parts according to their presence "fractures in geometry, fractures in nature" .However; fractures in nature differ from their counterparts in two main points:

-Self-similarity is limited and not subject to final continuity.

-Self-similarity between parts and their origins in nature is only an approximation and there is no perfect match, because of the multiplicity of natural forces that intervene to create those fractures, other than mathematical operations that are subject to the same equation.
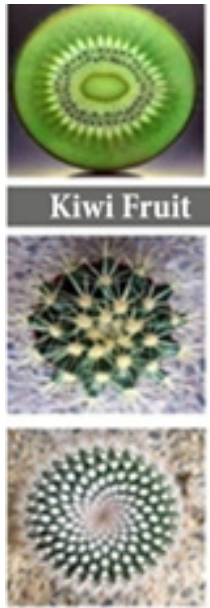

Cactuses

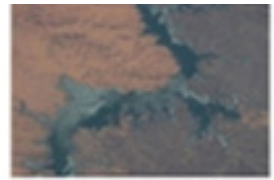

Naser Lake

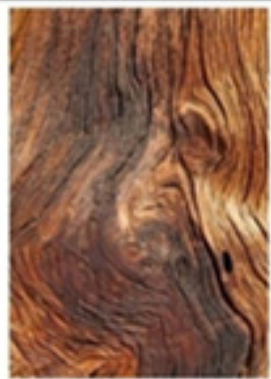

Wood

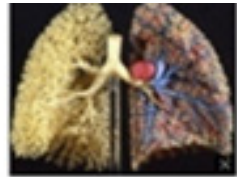

Lung

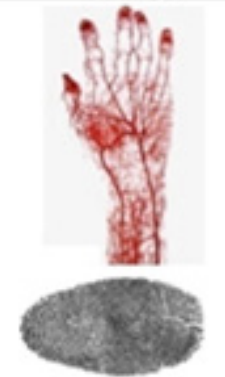

Capillaries

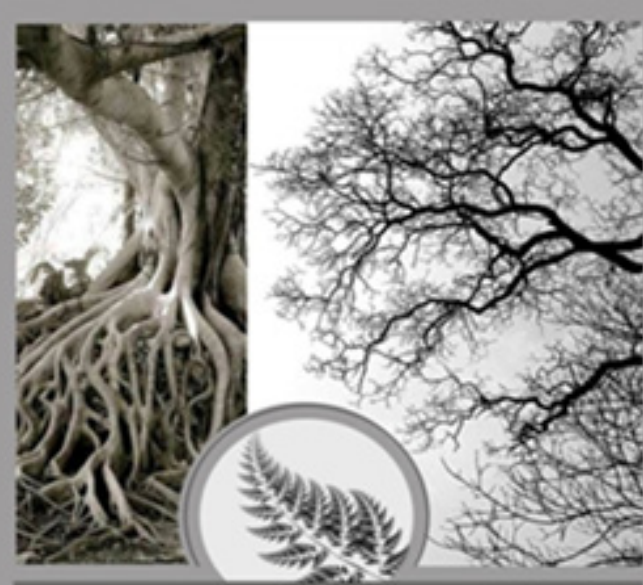

Morphological Structure of Tree

Figure 2 Models from unsystematic formations that are in nature and subject to fractional geometry

\section{Characteristics of fractional geometry}

Fractal geometry is characterized by many characteristics that have added new dimensions to achieve the aesthetics of contemporary furniture formation .The most important elements of these characteristics are self-similarity, fractional dimension, infinite diffusion, replacement and replacement, complexity.

\section{- Self-Similarity}

It means the similarity between the inner parts of the overall shape. If we enlarge any part of the shape, we get the original shape, and by analyzing any de- sign following the laws of self-similarity, we find that it consists of one element and then it is repeated at various scales [8]. This phenomenon was discovered by the American mathematician Benoit Mandelbrot when he analyzed the coastline of Britain and found that the coast curve always looks like the whole curve but with a different scale, we can divide the self-similarity into three sections: strong, average and weak as shown in Figure 3. 


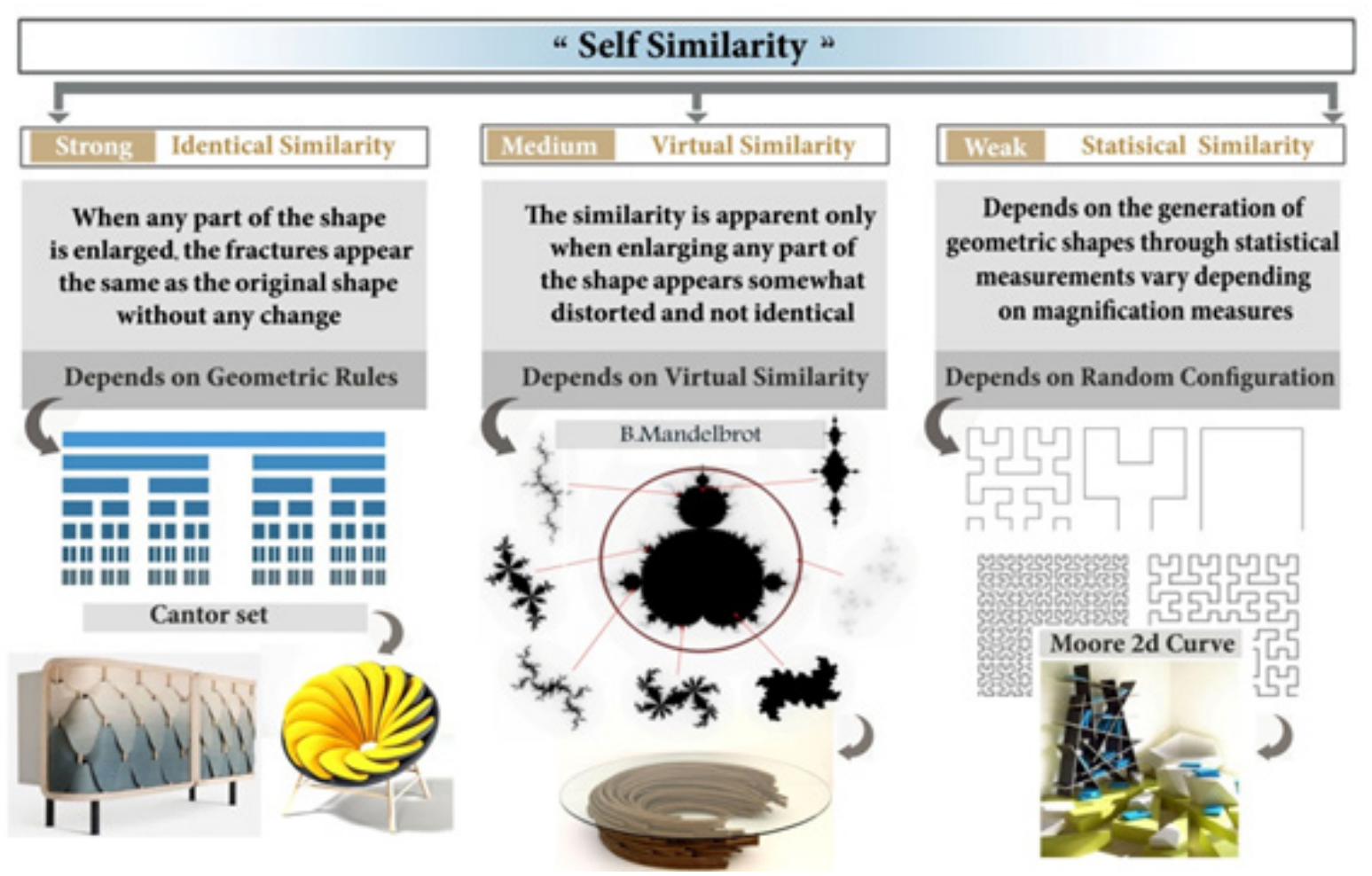

Figure 3 Self-similarity divisions and their reflection on contemporary furniture design

\section{- Fractal dimension}

While Euclidean geometry is concerned with the basic dimensions "first, second and third dimension", where the point is drawn in the zero dimension as it has no dimension, the straight lines are drawn in one dimension, while the flat geometric shapes are drawn in two dimensions and the three-dimensional shapes are drawn. However, these dimensions are not suitable for the composition of the partial shape, as the fractional dimension is not a numerical value [9], but the "Koch" curve is one example that illustrates the concept of a fractional dimension its dimensions are roughly between 1.26 and 2.1 analyses of chaotic processes.

\section{- Infinite Scalability}

Fractional shapes are characterized by infinite propagation. They contain countless details so that they cannot be measured, and the closer they look, the longer they appear in infinite formations.

\section{- Ability of replacement}

Fractional shapes are related to the principle of repetition according to a specific mathematical rule. By analyzing these forms we notice the occurrence of substitution by repeating the same unit within the original form and replace it with other forms so that it looks more complex than the form that precedes or follows, but it fills the same space. [4]

\section{- Complexity}

Complexity is considered one of the main features of fractional formations, which arises as a result of the high detail and multiplicity of highly interconnected elements that often interact and interfere with each other and with the system as a whole.

\section{Compatibility between the golden ratio and fractional geometry}

The Golden Ratio is one of the most important methods to achieve the aesthetic standards in design in general with mathematical reference, God Almighty deposited in the overall cosmic system, where it aims to achieve beauty, balance and harmony among all creatures, when researching and meditation in the continuous harmony of the charming nature abound with many creatures, as we discover that there is a common law closely related to the realization of beauty called "Golden Ratio". Everything that is desirable to our eyes must contain that proportion in dimensions or in a way that is consistent. This percentage has been used since ancient times through the succession of civilizations starting from the ancient Egyptian civilization and Greek civilization and Islamic civilization. The golden ratio is achieved by 
dividing a line into two parts, one small and the other large so that the ratio between the smallest to the largest is the same value for the ratio between the largest
The sum of the two together is 1.618 (Figure 4).

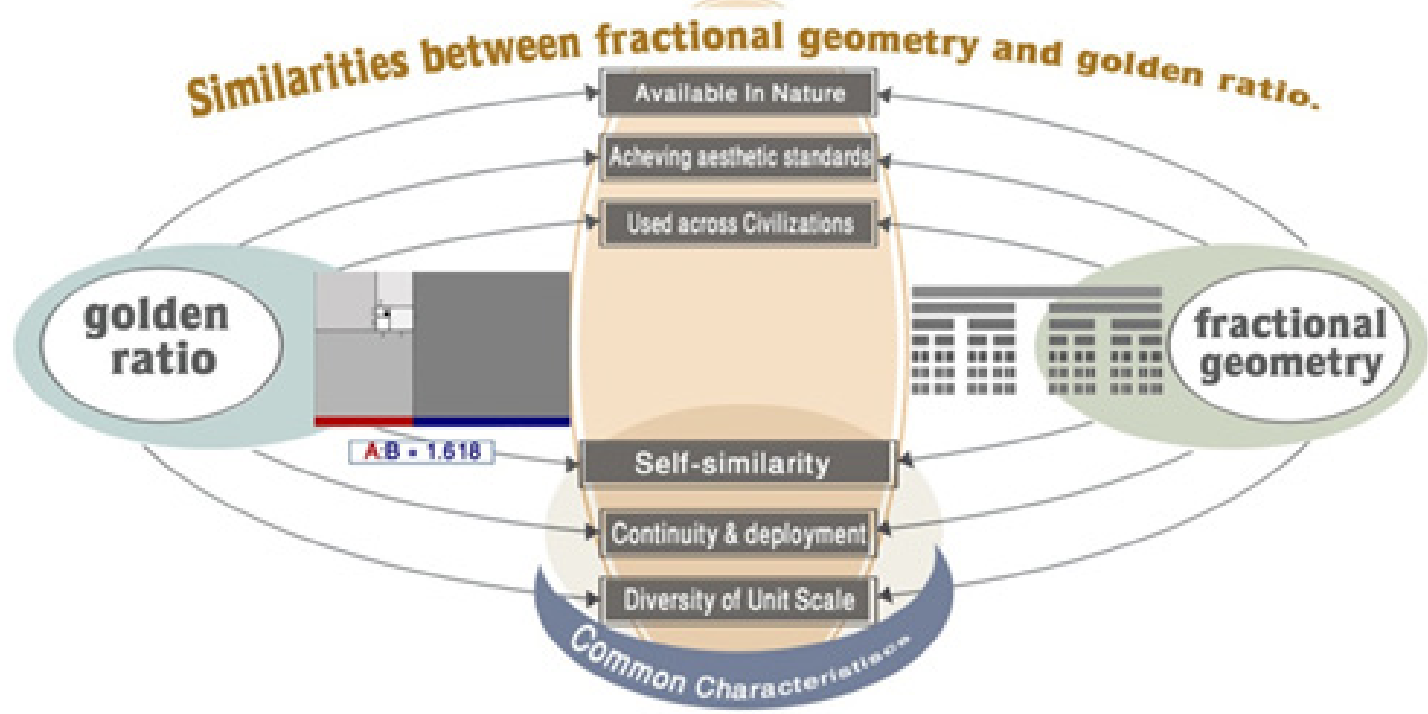

Figure 4 Similarities between fractional geometry and golden ratio

In the study of the sequence of "Leonardo Fionache", we will find that it expressed the golden ratio through a series of consecutive numbers $1,1,2,3,5,8,13$, $21,34 \ldots$ etc, to become a constant rate between those numbers to be 0.618 , and by analyzing that sequence, scientists found many fractional geometry properties such as self-similarity, fractal dimension, repetition and continuity, and the diversity of unit measurements between the rectangles and the resulting squares where each part became similar to the collection of other parts [3]. From here it is clear that there is a direct relationship between the golden ratio and fractional geometry where they share many characteristics, and if furniture designers are able to combine them, they will produce designs that are mathematically proportional and aesthetically compatible, subject to a tight engineering system.
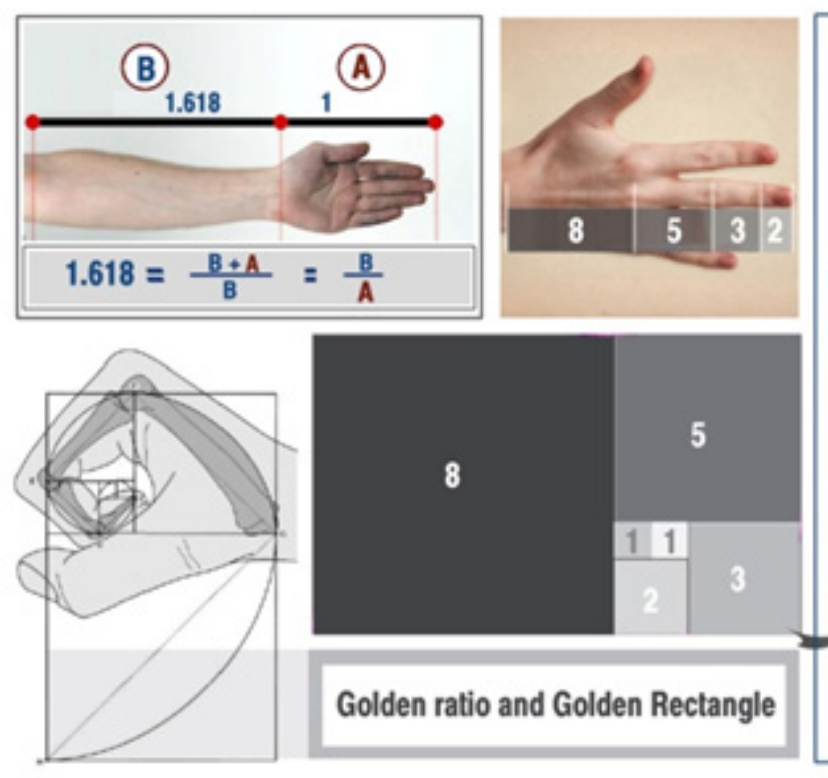

Figure 5 Golden Ratio and its application in the design field to obtain products with proportional relationships. 


\section{Fractal Geometry and the enrich of design}

\section{thinking}

The science of "fractal geometry" directly contributes to the development of the creative side of designers in general because of the possibilities that can open a fertile field of imagination, allowing the designer freedom to think and adopt atypical views, but rebellion on all that is normative, there is no room for the success of any design unless it is based on a "new idea or a contemporary trend" that is formulated materially in the design of what holds a creative form and content.

Through a conscious understanding of the principles of "fractal geometry", especially the self-similarity and infinite repetition on which it creates visual configurations and diverse design relationships, the designer moves out of the traditional framework and adds new dimensions and visions to the design process that will contribute. In building interrelationships between parts of the design work each other. In the field of design in general, we note that many designers have been influenced by their different specialties with the ideas and principles of fractional ge- ometry. This is evidenced by the emergence of some architectural formations. These spaces are functionally and aesthetically pleasing with renewed ideas. Then the furniture units confirmed this through the aesthetics of the exterior of the building on the basis of engineering where they were employed directly or indirectly, and this is evidenced by the design of Palmer House Architect Frank Lloyd Wright, located in Michigan, USA, which was built in 1951, and the idea of the design of the horizontal projection based on the overlap of equilateral triangles on various scales, resulting in a clear application of the concept of fractional geometry, which was maintained by the designer in the design of interior spaces Villa Papadanice "Paulo Portoghesi" as one of the models designed according to the principles of fractional geometry, which relies on the self-similarity of the element of the circle in the horizontal projection and then address the interior spaces, the walls vary between concave and convex and confirmed the continuity of the internal walls through the curve line and maintained self-similarity internally through the design of the roof.
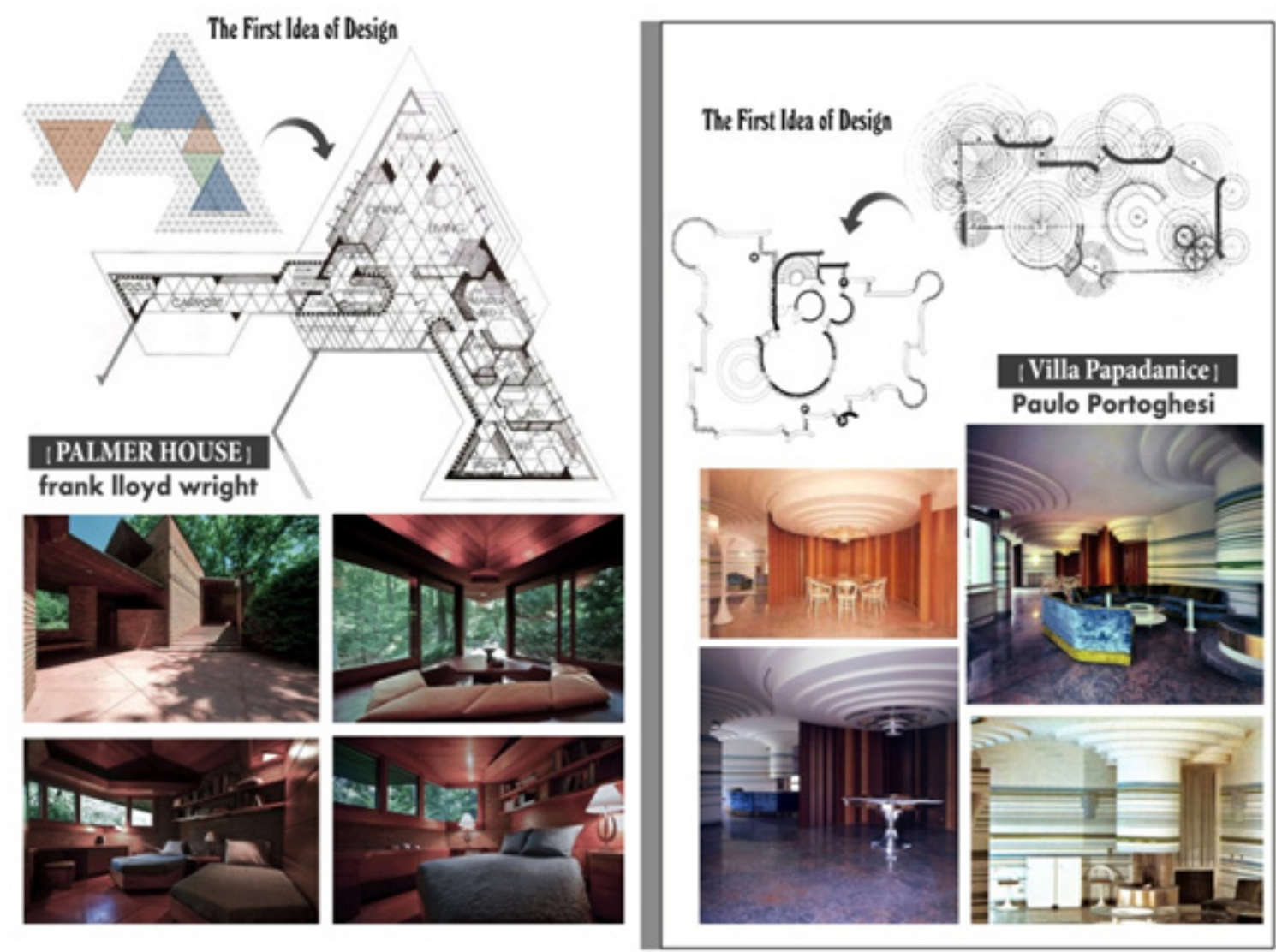

Figure 6 Reflection of the principles of fractional geometry on horizontal plane design and the design of interior spaces [14] 
Examples of philosophy inspired by the principles of fractional geometry include the interior design is the (Agri) church in Japan, located in the national park on the northwest coast of Kyushu Island, where the design-
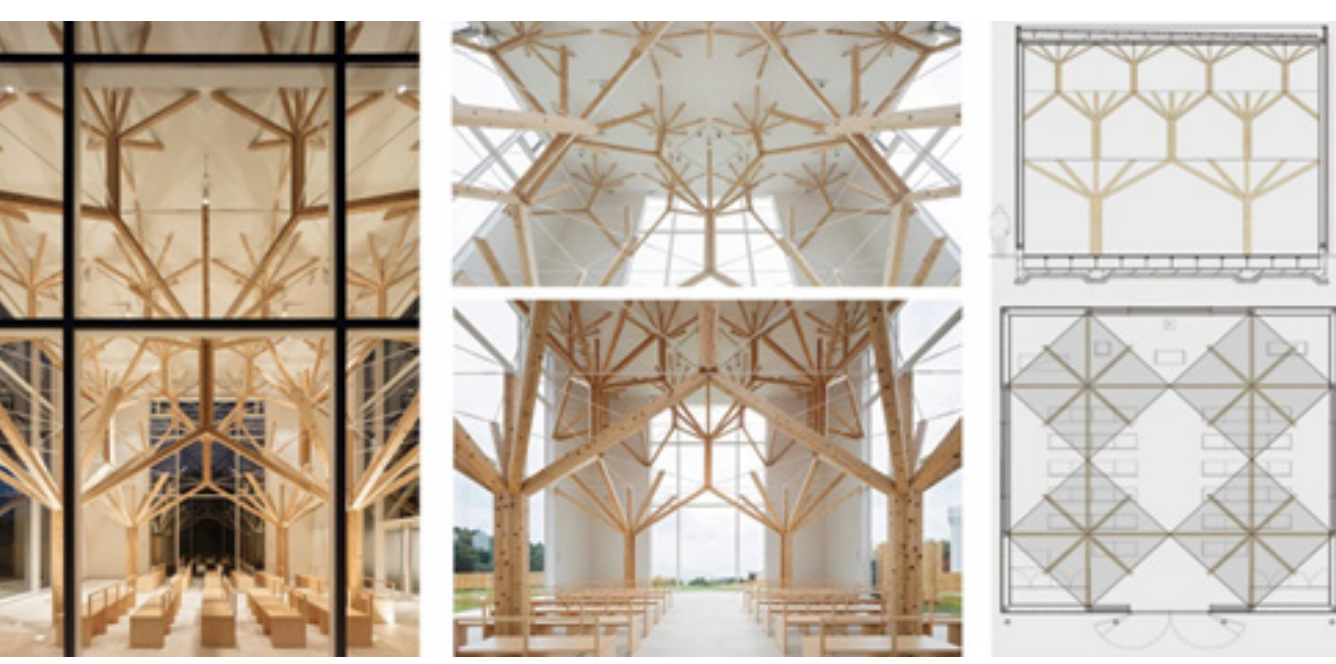

er wanted to mimic the nature of the surrounding forest formation merely. Wooden beams mimic tree branches through ascending symmetrical patterns spread across all parts of the void as shown in Figure (7).

Figure 7 Emphasis of repetition and self - similarity in the interior design of the (Agri) church in Japan [11]

In the field of furniture, many furniture designers have been influenced by the foundations and rules of building fractal shapes due to the advantage of the characteristics of "fractal geometry", we note the dependence of a large proportion of furniture designers on the property of repetition, whether regular or random repetition of the building unit, color, texture, direction etc.

Examples of regular repetition include the waiting seat of designer "Ricardo Blumer". Some furniture designers also rely on complexity, which arises from irregular repetition and morphological transformation as the modular changes in furniture units result in a shift from stability to chaos as shown in figure (8C). Some designers have also relied on the principle of proliferation and not the end by spreading the design units around one axis or more and we note this in the design of the seat "Fallen tree bench" and made of oak trees for the designer "Benjamin Graindorge" where he made sure to leave the ends of the branches of the tree as it is to emphasize continuity and infinite form as shown in figure (8D), which contributed positively to enrich the design thought and add new formative values.

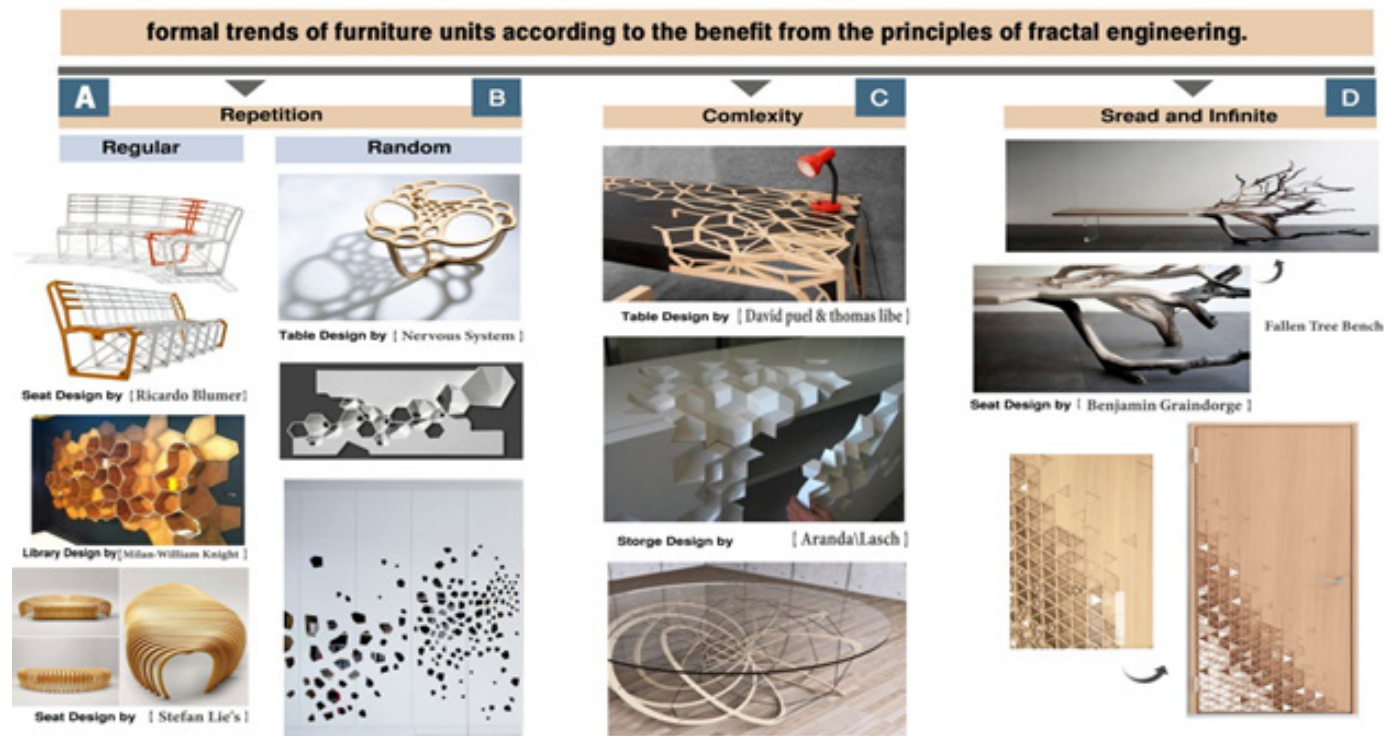

Figure 8 Shows the diversity in the formal trends of furniture units according to the benefit from the principles of fractal engineering [10] [12] [13] 


\section{Evolution of popular vocabulary lineup in light of fractal geometry}

Formation elements are a popular form with symbolic connotations and physical characteristics that gain its autonomy and its identity in the surrounding environment.

Taking care of these popular vocabularies and reformulating it according to some modern trends and sciences is nothing more than taking care of its sensual and symbolic connotations. Throughout human history, some of these vocabularies have been chosen, reformulated and employed because they have many characteristics that give them the power to survive over time [1], and is one of the most important sources of design creativity.

In reference to the vocabulary of the Nubian formation as one of the Egyptian popular elements we will find that it focused on some modular units that combine simplicity and spontaneity, whether they are "geometric, vegetarian, animal", and the researcher will analyze some geometric forms of Nubian folk vocabulary in an attempt to develop through fractional geometry.

\section{Analytical Studies}

The research in this part deals with some popular Nubian engineering popular units such as "square and triangle". These elements is not only a recording of the past, but a vocabulary formality carrying a symbolic dimension that combines the physical and moral side, which is also subject to growing experimentation through the ages reconstituting these units according to the characteristics of fractal geometry, taking into consideration the compatibility between the characteristics of fractional geometry and the rules of the golden ratio to reach a distinct aesthetics of contemporary furniture units.

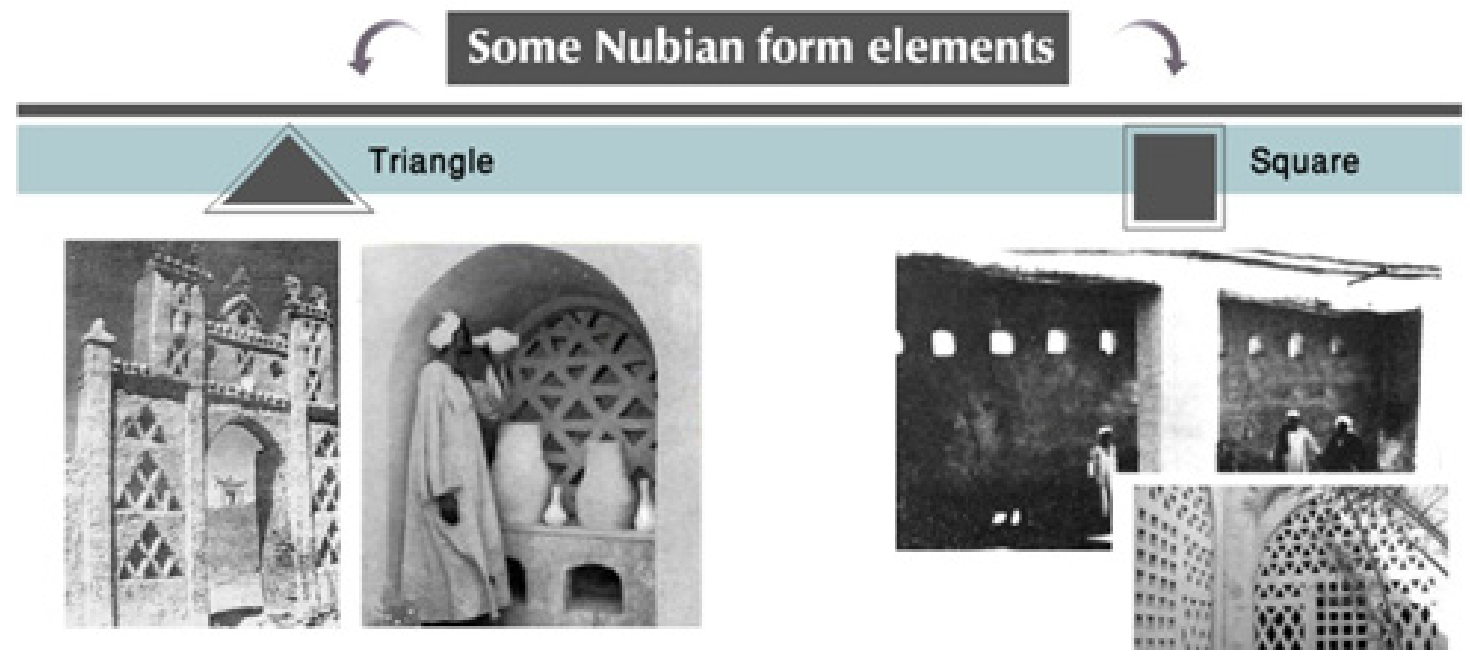

Figure 9 Some Nubian form elementstemporary furniture design

\section{8-1 The square as a single formation element}

The square is an important element in the Nubian folklore, also it is a sign of balance and sacredness as it carries balanced relationships towards the center point. It is used in the external walls in the form of energies to impart functional and aesthetic aspects. The researchers in this part will do some design experiments on it, taking advantage of the rules and foundations of fractal geometry and the rules of the Golden Ratio to obtain models designed for furniture units characterized by aesthetics of the external formation. First model
The first model achieved the combination of fractional geometry and the golden ratio through five main stages, starting with drawing the square and then repeating it with the diversity of the drawing scale by following the rules of drawing the golden rectangle, then the phase of reduction, addition, repetition and rearrangement of squares within each other to achieve continuity and stability. This model has "self-similarity and continuity" in addition to achieving the golden ratio between the resulting divisions with each other. 


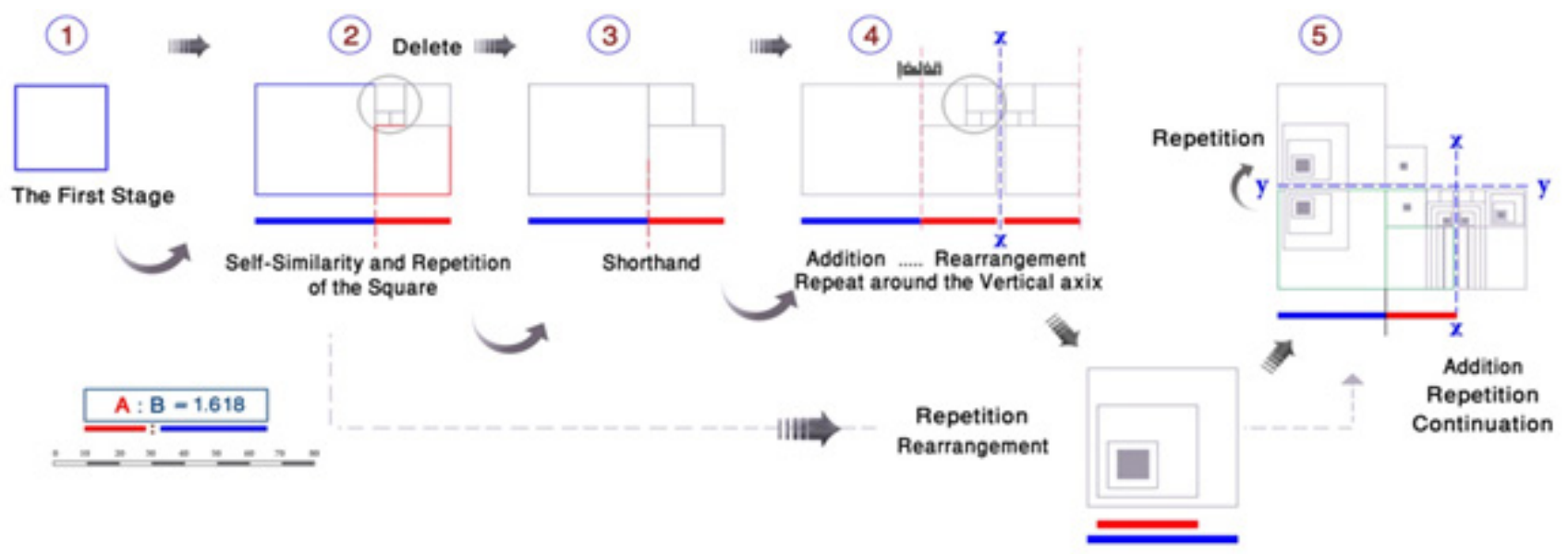

Figure 10 the main building unit of the first model and the stages of generating the proposed design
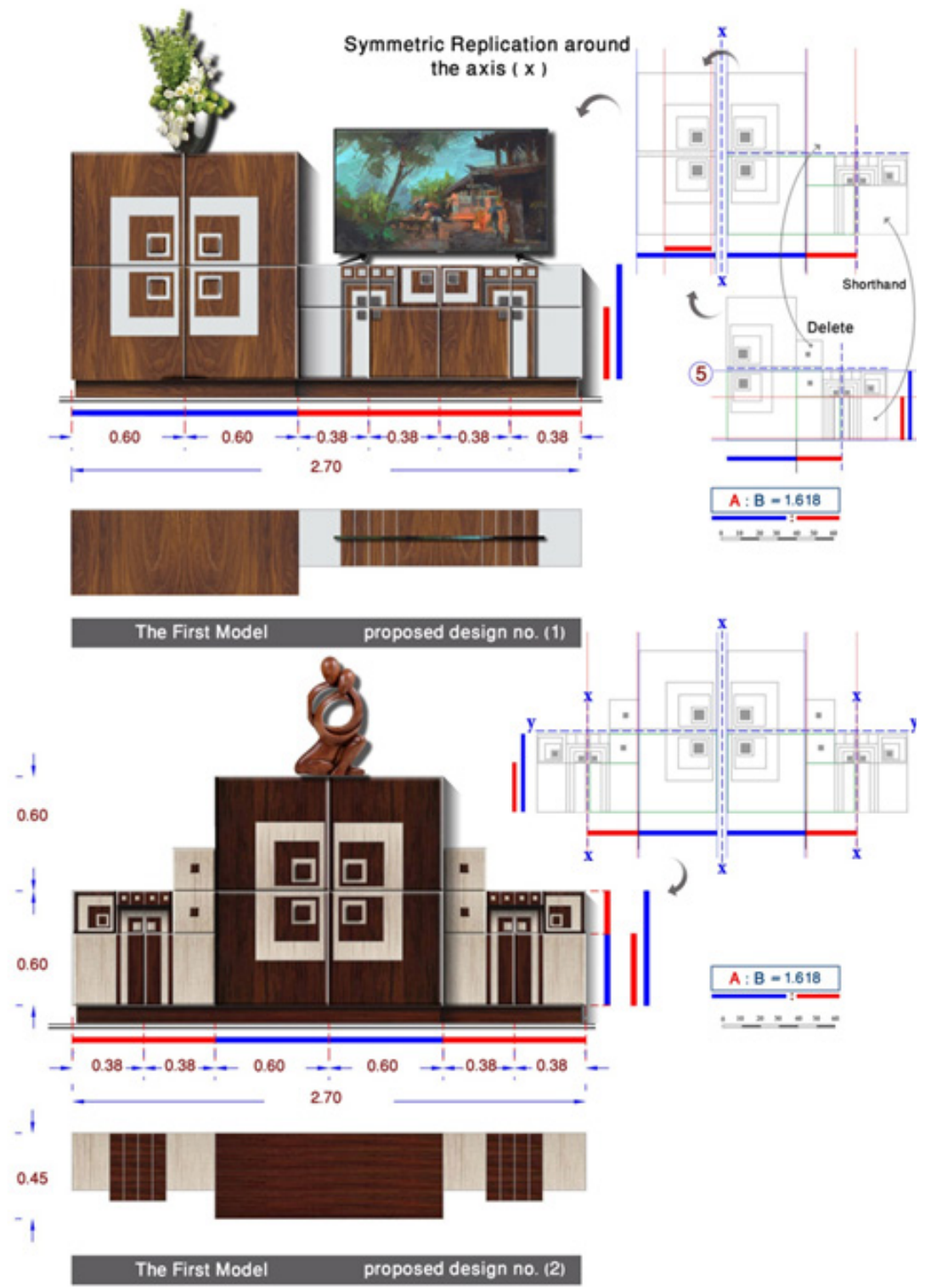

Figure 11 Design proposal no. (1), (2) for the first model . 


\section{Second model}

The second model contributed to the achievement of two aspects - the first side includes the use of proportions aesthetics between the boxes inside the golden rectangle with some simple additions, and trying to use them to fit some pieces of furniture, such as the design of a unit or a concealed as shown in Figure (12). While the second part was adopted on stages its more complex design included "shorthand, addition, repetition, continuity", that came up with two proposals, one for a storage unit and the other for a TV unit as shown in Figure (13).

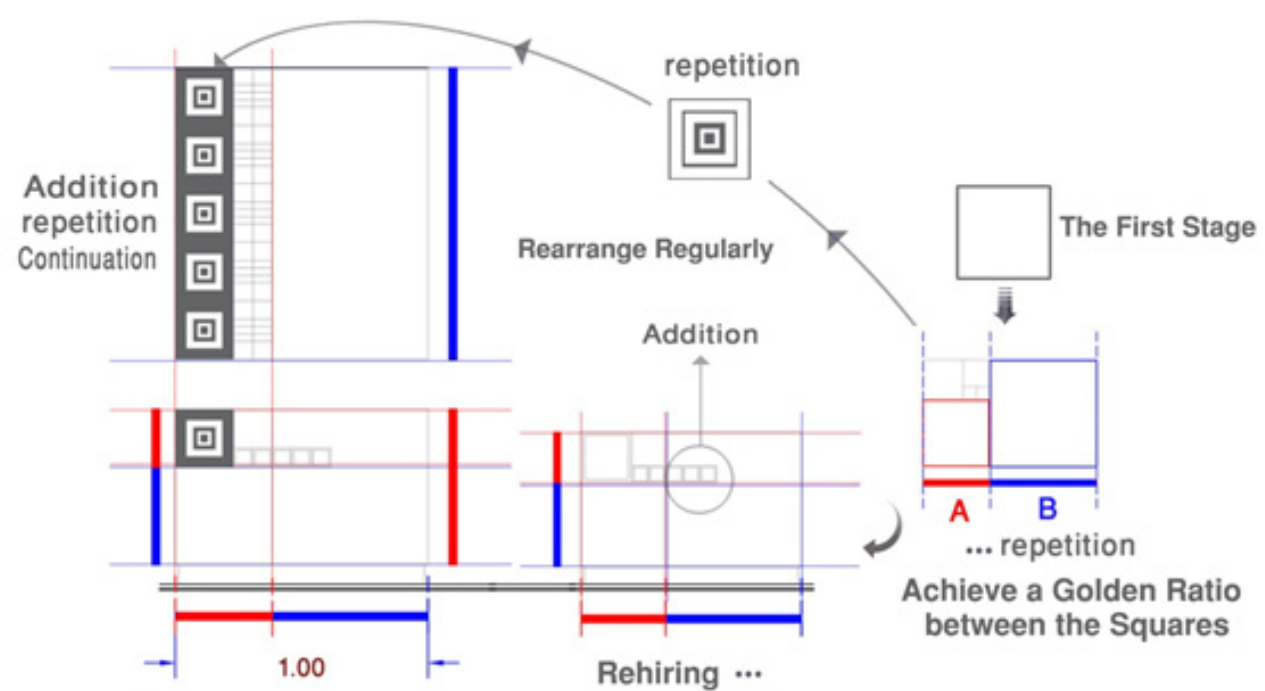

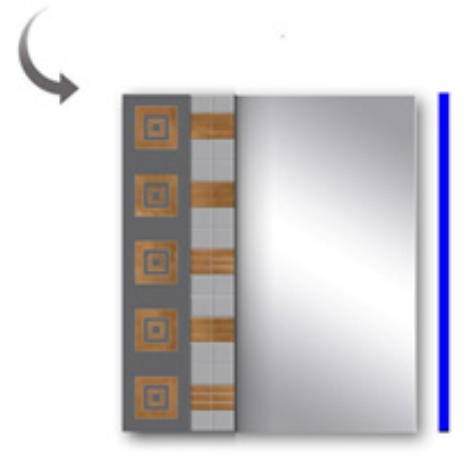
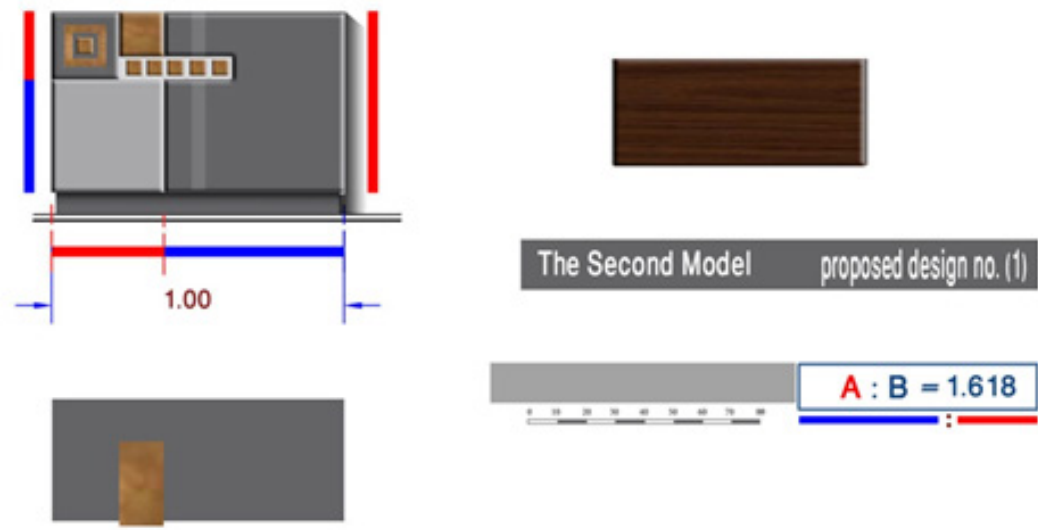

Figure 12 Structural stages of the proposed design no. $(1,2)$ - The second model 


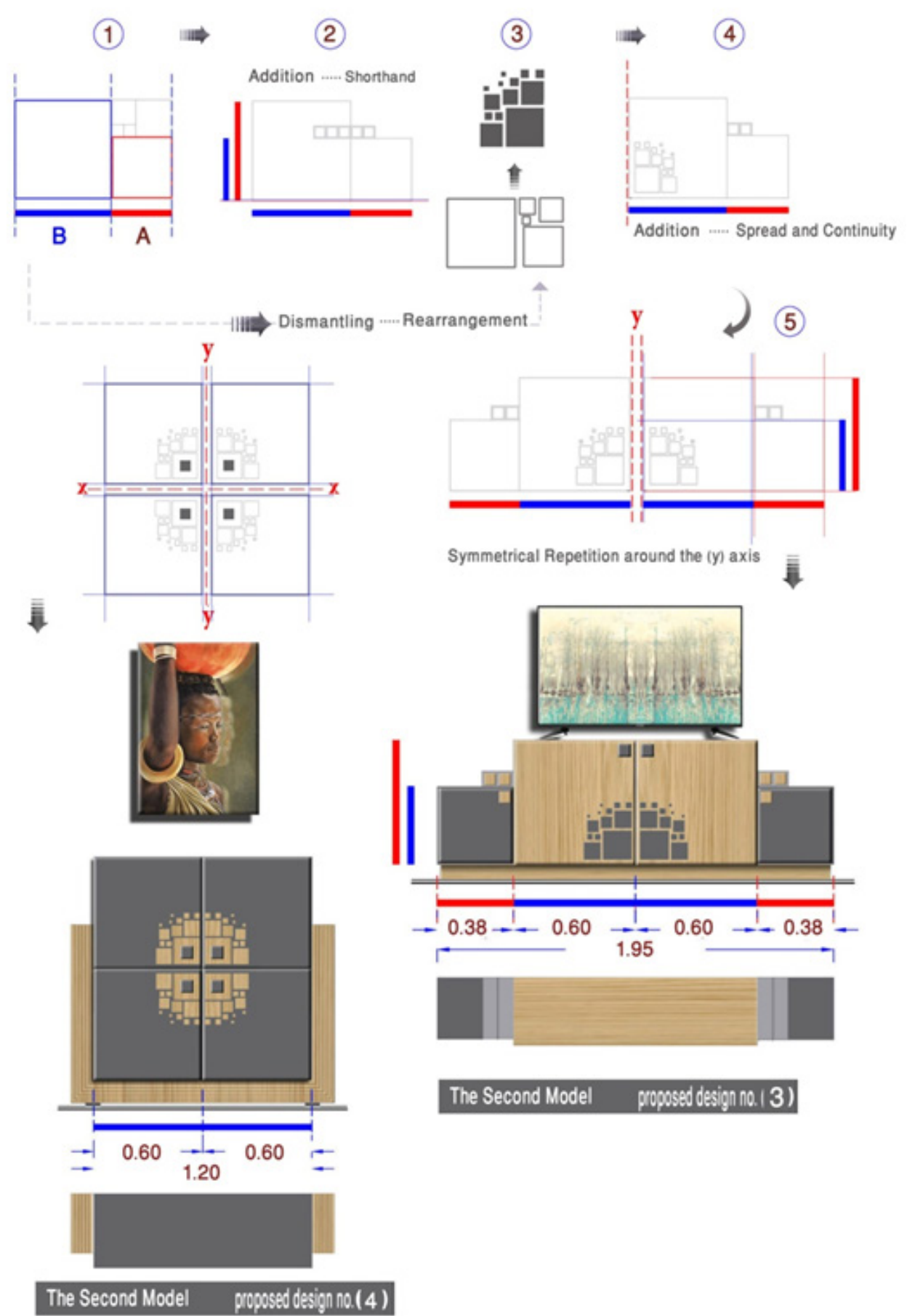

Figure (13) Structural stages of the proposed design no. (3), (4) - The second model

\subsection{The triangle as a singular form}

The triangle is especially important in the Nubian folklore because of its symbolic, environmental and societal connotations. It is endless in many areas, especially the manufacture of ceramics, wicker and textiles. The architects approached using triangle to overcome poor lighting and ventilation due to privacy, also not to allow the presence of windows overlooking the street, and to make decorative holes in triangular formations using mud and clay .The researchers in the next model used triangle as one of the popular elements and re-formulated it in modular design contemporary furniture. 


\section{First model}

The first model used an isosceles triangle where it applied some of the characteristics of fractal geometry through different design fundamentals such as repetition, displacement, addition and reduction, taking into consideration achieving the golden ratio in the emerging division relations. The design of the center table shown in figure (15) combined in both the philosophy of design and the shape of the "triangle", which forms one of the most popular decorative elements that had both the characteristics of fractional geometry and the rules of the golden ratio

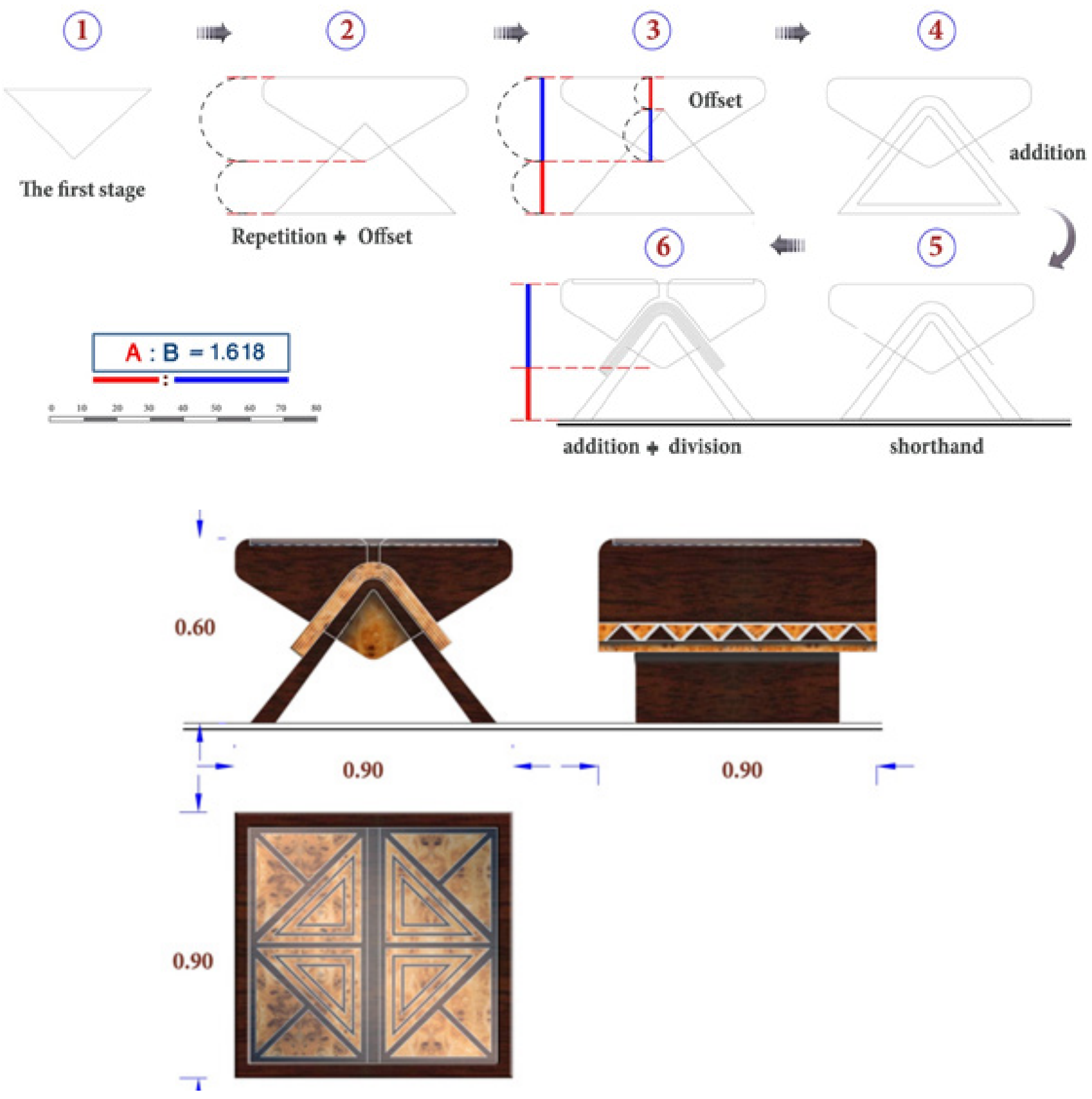

Figure 15 the main structural stages of the first model and the stages of generating the proposed design. 


\section{Second model}

The second model relied on "complexity and self-similarity", as one of the fractal geometrical properties that was applied through the relationships of repetition, merging, reduction, and an addition to obtain the proposed design.
(1)

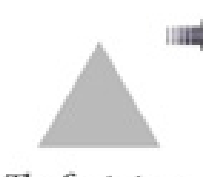

The first stage

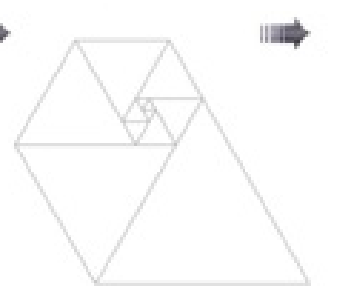

Repetition $\$$ Diversity of the scale
(2)

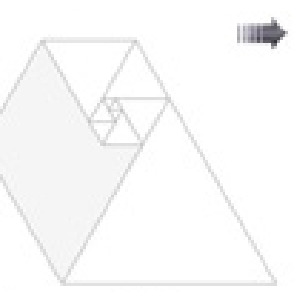

Merge
(3)

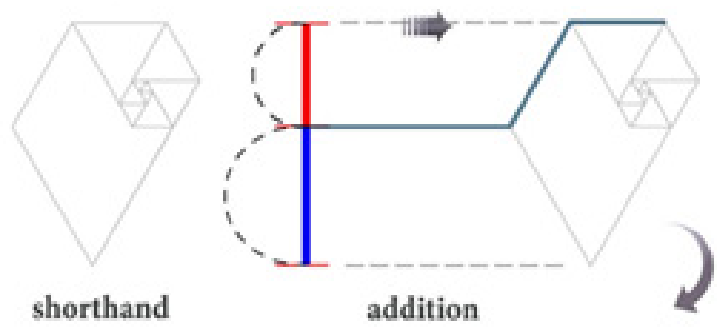

(5)

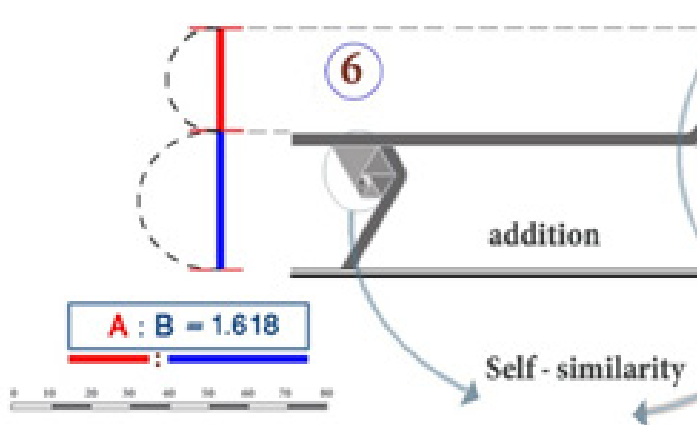

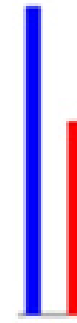
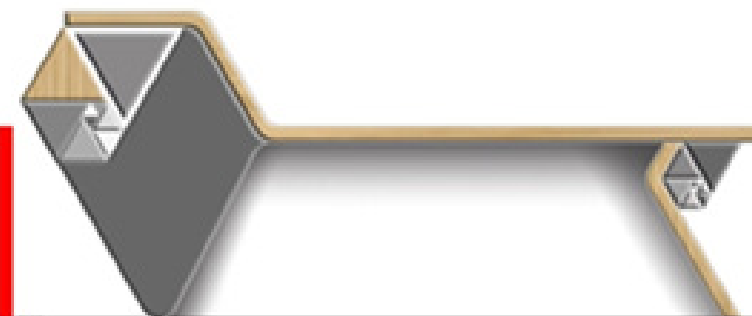

0.50

Repetition
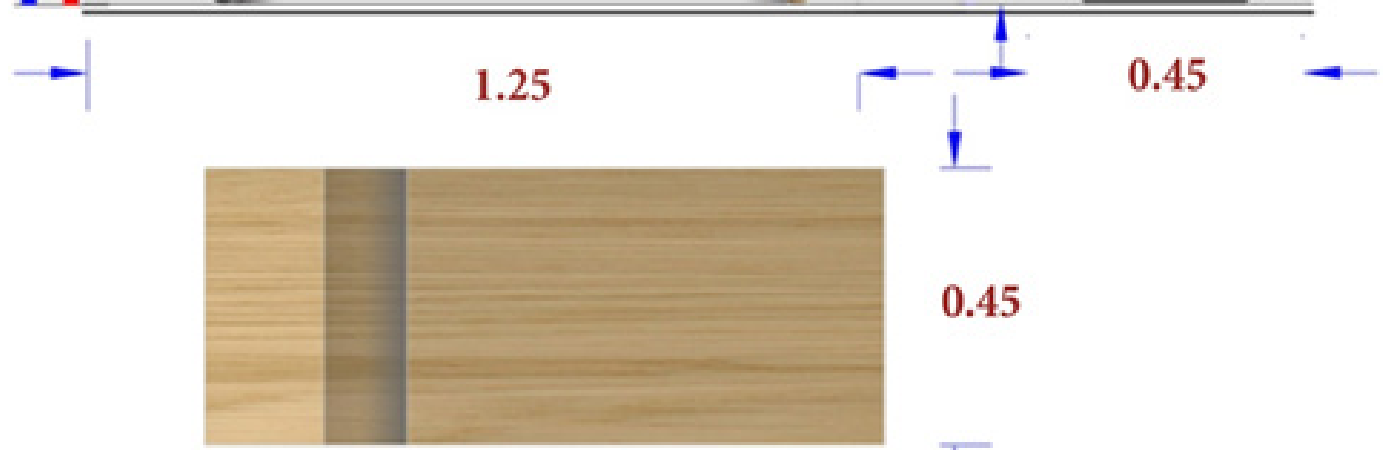

0.45

I

Figure 16 the triangle as the main design element and the stages of generating the proposed design -The second model 


\section{Results}

Research and analysis resulted to the following points: 1- There is a close relationship between fractal geometry and the golden ratio, both of which contribute directly to the realization of the aesthetics of the external formation of furniture units.

2 - There are common characteristics between fractional geometry and the golden ratio such as self-similarity, continuity, diffusion and diversity of the scale, and they are both deposited by God in most of natural beings.

\section{Recommendations}

1- The necessity of combining modern science with furniture design science to reach new design results that keep pace with future development.

2 - Academic institutes need to adopt courses interested in studying modern applications of computer programs and link them to the design process in order to benefit from them in the generation of design ideas, which is positively reflected on the intellectual and design output.

\section{References}

\section{Arabic references}

1- Ashraf Hussein Ibrahim, (2013), Popular Cultures "Studies in Customs, Arts and Media", Philadelphia University Press, p. 404.

2- Asmaa Shaker Nehmeh, (2014), "Aesthetics of Engineering Formations, Scenography of Theatrical Presentation", published research, Journal of Humanities, University of Babylon - Iraq, p. 72.

3- Francesch Shing, (2013), Architecture "Mass - Space System", translated by Ahmad Al-Khatib, Egyptian Anglo library, p. 303.

4 - Iman Ibrahim Badr, (2017), "Design methods in the application of fracture geometry in the interior design of tourist facilities," International Design Journal, Issue 7 number 2, p. 92.

5 - Mohamed Elsaid Ali Asal, (2015), "Fractals and mathematical algorithms as an entrance to enrich the digital graphic arts", the first international conference of plastic arts - Faculty of Fine Arts in Luxor -GanoubElwady University, p. 3.

6- Reham Mohammed Abdul Salam, (2017), "The theory of Fractal between experimentation and application in the design of the printing surfaces of pendants fabrics," Journal of Architecture and Islamic Arts, Issue No. 8, p. 2.

7- The Holy Quran, Surat Al-Nahl (verse 6).

\section{English references}

8-Didier Gonze,(2014)"Fractals: theory and applications" ,Unité de ChronobiologiThéorique Service de Chimie Physique - CP 231 UniversitéLibre de Bruxelles Belgium, p. 2 .

9- James Gleick,(2008), “'Chaos - Making a new Science “, Publisher: Penguin Books; Anv Repedition, p. 99.

\section{Internet Websites References}

10-www.bonluxat.com/a/riccardo-blumer-and-matteoborghi-ghisa-bench.html

11-www.designboom.com/architecture/yu-momoeda-architecture-office-agri-chapel-japan

12- www.flickr.com/photos/arandalasch

13-www.ignant.com/a-fallen-tree-bench-by-benjamingraindorge

14-www.improvisedlife.com/horizontally-striped-walls 